\title{
Cuff-less J Pouch Anal Stapling Anastomosis for Ulcerative Colitis
}

\author{
HIDEJIRO KAWAHARA ${ }^{1}$, TADASHI AKIBA ${ }^{1}$ and KATSUHIKO YANAGA ${ }^{2}$ \\ ${ }^{1}$ Department of Surgery, Kashiwa Hospital, Jikei University School of Medicine, Chiba, Japan; \\ ${ }^{2}$ Department of Surgery, Jikei University School of Medicine, Tokyo, Japan
}

\begin{abstract}
Background/Aim: For ulcerative colitis, J pouch anal anastomosis with preserved rectal cuff had been popularized with its acceptable defecation function. However, some complications associated with rectal cuff after surgery have been reported. We are performing a novel procedure, laparoscopic cuff-less $J$ pouch anal stapling anastomosis. Patients and Methods: From January 2014 to December 2016, ten patients with ulcerative colitis, including three with concomitant cancer underwent this procedure. J pouch anal anastomosis was performed at the dentate line in all patients by our original procedure. In a manometric examination of all patients more than one year after the operation, maximum resting pressure was $68.0(52-84) \mathrm{mmHg}$, maximum squeeze pressure was 101.7 (87-121) $\mathrm{mmHg}$, length of high-pressure zone was 32.3 (30-35), and none had observed rectoanal reflex. Good defecation was confirmed by defecography. Conclusion: Cuff-less $J$ pouch anal stapling anastomosis seems to be a useful procedure for patients with ulcerative colitis.
\end{abstract}

$\mathrm{J}$ pouch anal anastomosis with preserved rectal cuff had been popularized with its acceptable defecation function for ulcerative colitis. However, some complications associated with rectal cuff after surgery have been reported $(1,2)$. We are performing a novel procedure, laparoscopic cuff-less J pouch anal stapling anastomosis.

\section{Patients and Methods}

From January 2014 to December 2016, ten patients with ulcerative colitis, including three with concomitant cancer underwent this procedure. Anal manometry was carried out by Pock Monitor

Correspondence to: Associate Prof. Hidejiro Kawahara, Department of Surgery, Kashiwa Hospital, Jikei University School of Medicine, 163-1 Kashiwashita, Kashiwashi, Chiba 277-8567, Japan. Tel: +81 471641111 Ext. 3421, Fax: +81 471633488, e-mail: kawahide@ jikei.ac.jp

Key Words: Cuff-less, stapling anastomosis, J pouch, ulcerative colitis.
GMMS-100 system (STAR MEDICAL, INC., Tokyo, Japan) one year after surgery. Maximum resting pressure, maximum squeeze pressure, length of high-pressure zone, and rectoanal reflex were measured. Defecational function was evaluated by defecography.

Surgical technique. After laparoscopic total mesorectal mobilization to the anal canal, rectal transection was performed at the upper edge of the anal canal by firing three sets of $30 \mathrm{~mm}$-long staplers. If a patient is male, the purpose of the first firing is to incise the rectourethralis muscle to separate the rectum and urethra (Figure 1). After the rectal transection, the anal canal seems to be a wall from the anal side view when six stay sutures were placed around the anal sphincter to expose the anal canal (Figure 2). J pouch anal anastomosis was performed by the double stapling technique using a $25 \mathrm{~mm}$ circular stapler through the anus. J pouch anal anastomosis is created at the dentate line because the oral side of the anal canal from the dentate line is resected by a circular stapler (Figure 3). A temporary stoma was constructed in all patients and was closed 3 months later.

\section{Results}

The patients had a mean age of 42.0 years (range $=20-74$ years), and 7 of them were male. The three of them had concomitant cancer. The mean postoperative hospital stay was 16.3 days (range $=14-18$ days) (Table I). J pouch anal anastomosis was created at dentate line in all patients. In a manometric examination of all people more than one year after the operation, maximum resting pressure was $68.0 \mathrm{mmHg}$ (range $=52-84 \mathrm{mmHg}$ ), maximum squeeze pressure was $101.7 \mathrm{mmHg}$ (range $=87-121 \mathrm{mmHg}$ ), length of high-pressure zone was 32.3 (range $=30-35) \mathrm{mm}$, and none was observed rectoanal reflex (Table I). The descent of the perineum and linearization of the anorectal angle were observed. 11 barium were discharged by some abdominal pressures. Good defecation was confirmed by defecography (Figure 4).

\section{Discussion}

As to surgical procedures for ulcerative colitis, restorative proctocolectomy with ileal pouch-anal anastomosis (IPAA) has been the widely accepted. The preserved rectal cuff which did not destroy rectoanal neuromuscular structure in 


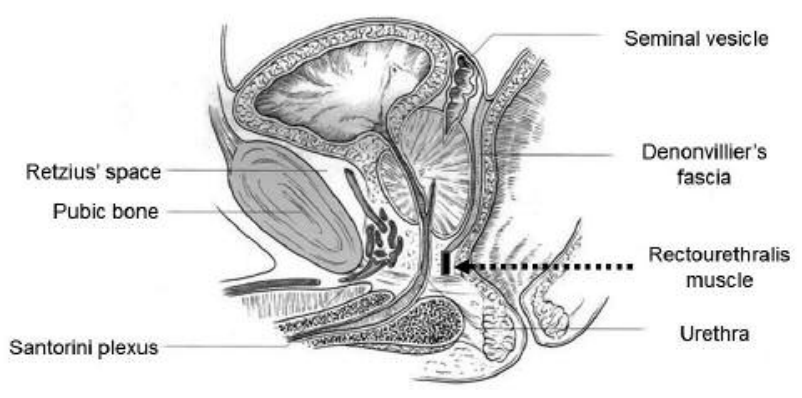

Figure 1. Anatomical guidance. The rectourethral muscle locates between the rectum and the urethra.

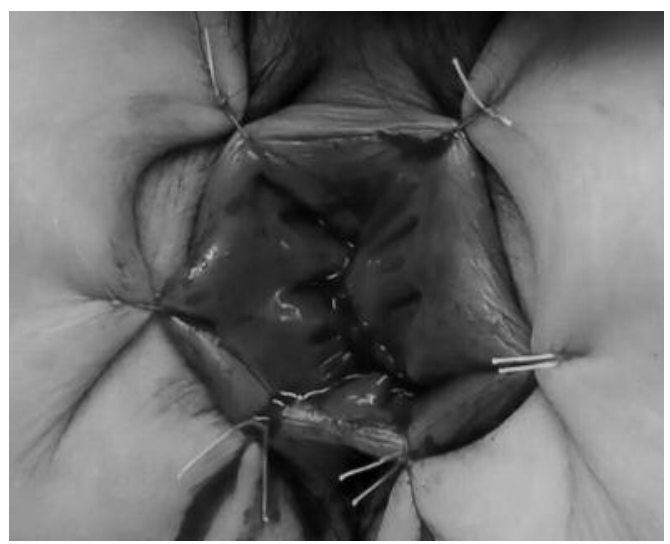

Figure 2. View of the anus before anastomosis. After rectal transection, the anal canal looks like a wall from the anal side view when six stay sutures were placed around the anal sphincter to expose the anal canal.

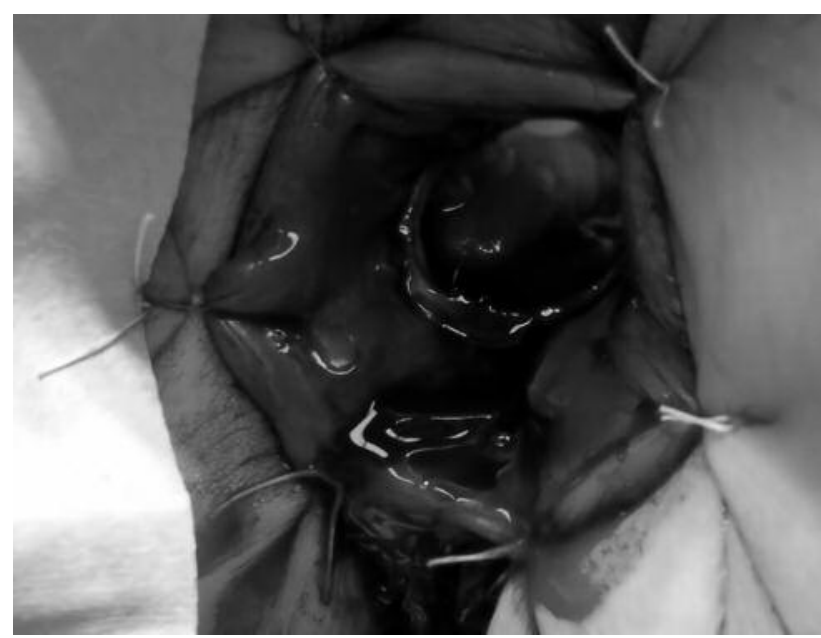

Figure 3. View of the anus after anastomosis. An anastomosis is created at the dentate line because the oral side of the anal canal from the dentate line is resected by a circular stapler.
Table I. Characteristics of the patients.

\begin{tabular}{lc}
\hline Variable & $\mathrm{n}=10$ \\
\hline Age (years) & $42.0(20-74)$ \\
Gender & $7(70)$ \\
$\quad$ Male & $3(30)$ \\
Female & $303.4(260-335)$ \\
Duration (min) & $49.0(0-200)$ \\
Bleeding (ml) & $16.3(14-18)$ \\
Postoprerative hospital stay (days) & $3(30)$ \\
Concomitant cancer & $68.0(52-84)$ \\
Maximum resting pressure (mmHg) & $101.7(87-121)$ \\
Maximum squeeze pressure (mmHg) & $32.3(30-35)$ \\
Length of high-pressure zone (mm) & $0(0)$ \\
Rectoanal reflex positive &
\end{tabular}

The data are presented as mean (range) or as $\mathrm{n}(\%)$.

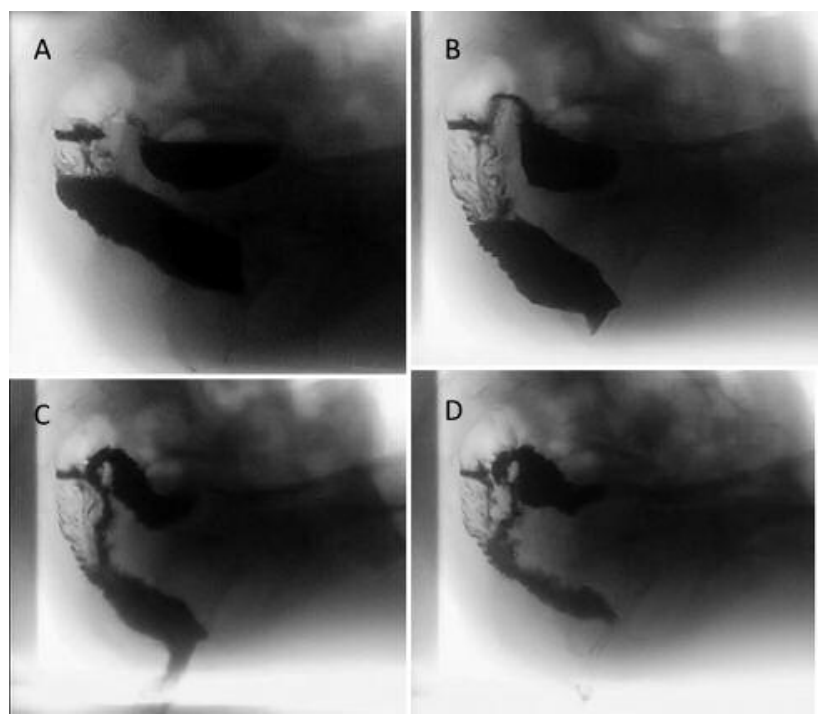

Figure 4. Defecography one year after surgery. A: Resting, B: Descent of the perineum and linearization of the anorectal angle, $C$ : Discharge by increased abdominal pressures, D: After discharge.

IPAA was considered to obtain good defecation function after surgery (3). However, some complications associated with rectal cuff after surgery have been reported $(1,2)$. Intersphincteric resection (ISR) is a surgical procedure which makes anastomosis between the intestine and the anus directly without a rectal cuff. Certain reports described that ISR has good postoperative defecation function (4). In restorative proctocolectomy with IPAA, defecation function after DST was superior to that after hand-sewn anastomosis (5). Therefore, we tried to start cuff-less surgery since 2014. 
When we tried rectal transection just above the anal canal with a linear stapler, the anterior wall of the rectum just above the anal canal could not be transected anatomically (5). However, after cutting rectourethralis muscle by a 30$\mathrm{mm}$ length stapler, rectal transection was easily performed just above the anal canal. J pouch anal anastomosis was created at the dentate line because oral side of the anal canal from the dentate line was resected by a $25 \mathrm{~mm}$ circular stapler.

With regard to defecation function after surgery, the measurements obtained by manometry, maximum resting pressure, maximum squeeze pressure, and length of highpressure zone, were similar to reported normal values (6). Furthermore, good defecation was confirmed by defecography.

Long-term follow-up is necessary, but Cuff-less $\mathrm{J}$ pouch anal stapling anastomosis seems a useful procedure for patients with ulcerative colitis.

\section{Conflicts of Interest}

The Authors have no conflicts of interest to disclose and received no financial support for this study.

\section{References}

1 Hueting WE, Buskens E, van der Tweel I, Gooszen HG and van Laarhoven CJ: Results and complications after ileal pouch anal anastomosis: a meta-analysis of 43 observational studies comprising 9,317 patients. Dig Surg 22(1-2): 69-79, 2005.
2 Ryoo SB, Oh HK, Han EC, Ha HK, Moon SH, Choe EK and Park KJ: Complications after ileal pouch-anal anastomosis in Korean patients with ulcerative colitis. World J Gastroenterol 20(23): 7488-7496, 2014.

3 Shoji Y, Kusunoki M, Fujita S, Yamamura T and Utsunomiya J: Functional role of the preserved rectal cuff in ileoanal anastomosis. Surgery 111(3): 266-273, 1992.

4 Saito N, Moriya Y, Shirouzu K, Maeda K, Mochizuki H, Koda $\mathrm{K}$, Hirai T, Sugito M, Ito $\mathrm{M}$ and Kobayashi A: Intersphincteric resection in patients with very low rectal cancer: a review of the Japanese experience. Dis Colon Rectum 49(10 Suppl): S13-22, 2006.

5 Choi JS, Potenti F, Wexner SD, Nam YS, Hwang YH, Nogueras JJ, Weiss EG and Pikarsky AJ: Functional outcomes in patients with mucosal ulcerative colitis after ileal pouch-anal anastomosis by the double stapling technique: is there a relation to tissue type? Dis Colon Rectum 43(10): 1398-1404, 2000.

6 Frenckner B and Euler CV: Influence of pudendal block on the function of the anal sphincters. Gut 16(6): 482-489, 1975.
Received August 24, 2017

Revised September 7, 2017

Accepted September 8, 2017 